\title{
Human fetal pancreatic insulin-producing cells proliferate in vitro
}

\author{
Mugdha V Joglekar, Vinay M Joglekar ${ }^{\mathbf{1}}$, Sheela V Joglekar ${ }^{\mathbf{1}}$ and Anandwardhan A Hardikar \\ Stem Cells and Diabetes Section, Lab 10, National Center for Cell Science, Ganeshkhind Road, Pune MH 411007, India \\ ${ }^{1}$ Shree Seva Medical Foundation, Shirwal, Satara MH 412001, India \\ (Correspondence should be addressed to A A Hardikar; Email: anand@isletbiology.com)
}

\begin{abstract}
There have been considerable efforts towards understanding the potential of human pancreatic endocrine cells to proliferate and transition into mesenchymal cell populations. Since rodent studies have demonstrated that mouse insulinproducing cells do not proliferate in vitro, a similar possibility has been considered for human islet endocrine cells. Considering the inherent differences in mouse and human pancreatic islets, we decided to assess the potential of human fetal pancreatic insulin-producing cells to proliferate in vitro. We studied the proliferative potential of human fetal pancreatic islet-derived populations from second or third trimester fetal pancreas and characterized the cells that grow out during their expansion. We have used seven different approaches including in situ hybridization and immunostaining, quantitative estimation of multiple gene transcripts in
\end{abstract}

populations as well as in single cells, clonal analysis of islet cells, assessment of heritable marks of active insulin promoter, and thymidine analog-based lineage tracing. Our studies demonstrate that human fetal pancreatic insulin-producing cells proliferate in vitro to generate mesenchymal cell populations. Interestingly, epigenetic modifications that mark open chromatin conformation of insulin promoter regions are retained even after a million fold expansion/proliferation in vitro. These findings demonstrate that hormone-producing cells in pancreatic islets proliferate in vitro and retain epigenetic marks that characterize an active insulin promoter. Such in vitro-derived mesenchymal cells may be of potential use in cellreplacement therapy for diabetes.

Journal of Endocrinology (2009) 201, 27-36

\section{Introduction}

One of the main areas of debate in endocrine pancreas biology has been in understanding the potential of islet $\beta$-cells to proliferate. Though pancreatic islet cells are believed to be terminally differentiated cells that may not be able to proliferate and/or dedifferentiate, recent studies in adult human islet cells have demonstrated that insulin-producing cells can proliferate to generate mesenchymal-like cells in vitro (Russ et al. 2008). Since progenitor cells generated from pancreatic islets are known to retain epigenetic marks of active insulin promoter (Mutskov et al. 2007), such islet-derived cells are believed to be of potential importance for cell replacement therapy in diabetes. Though mouse insulinproducing cells are shown to undergo postnatal duplication (Dor et al. 2004) suggesting their proliferative potential, several studies carried out in the past year have demonstrated the limitations in proliferation of mouse insulin-producing cells in vitro (Atouf et al. 2007, Chase et al. 2007, Morton et al. 2007, Teta et al. 2007, Weinberg et al. 2007). These studies propose that $\beta$-cells in adult mouse islets die off or are diluted by rapidly proliferating populations that originate from expansion of pre-existing mesenchymal cells within islets. A similar possibility is considered for the mesenchymal cells generated from human pancreas. Though studies in mice provide convincing evidence towards the inability of adult mouse pro-insulin $/ P d x 1$-expressing cells to proliferate in vitro, it is inappropriate to directly extrapolate these findings to human islet $\beta$-cells. Recent studies by Russ et al. (2008) demonstrate the ability of adult human $\beta$-cells to proliferate in vitro. These investigators labeled single cells isolated from human islets by a dual virus system which specifically labels $\beta$-cells. Lineage tracing demonstrates the ability of adult human pancreatic $\beta$-cells to dedifferentiate and proliferate in culture dishes. In support of these observations, we describe several other techniques that we employed to assess the potential of human fetal pancreatic islets to proliferate in vitro. Our data demonstrate that human fetal pancreatic insulincontaining cells proliferate in vitro following exposure to serum-containing medium (SCM).

\section{Materials and Methods}

\section{Cell culture}

Second trimester $(n=49)$ and third trimester human fetal pancreas $(n=3)$ were collected within $1 \mathrm{~h}$ after medical termination of pregnancy and prior informed consent as per the institutional guidelines for use of human tissues. 
Third trimester fetuses were collected only in cases where continuation of pregnancy was life threatening to the mother. All procedures were approved by Institutional Ethical Committee. Islets were isolated following previously published protocols for fetal (Kover \& Moore 1989) or adult (Ricordi et al. 1989) human pancreatic islet isolation. Handpicked islets were then seeded in $75 \mathrm{~cm}^{2}$ tissue culture-treated flasks with $10 \mathrm{ml}$ CMRL-1066 medium (Gibco) containing $5.5 \mathrm{mM}$ glucose, $2 \mathrm{mM}$ L-glutamine, $10 \%$ (v/v) fetal bovine serum, and $10 \mathrm{ng} / \mathrm{ml}$ epidermal growth factor (EGF; SCM). For depleting $\beta$-cells, freshly isolated islets were exposed overnight to $1 \mathrm{mM}$ streptozotocin (STZ), a $\beta$-cell-specific toxin and maintained in SCM thereafter. For clonal analysis, freshly isolated islets were dispersed with trypsin and seeded in 96-well plates at a density of 40 cells per plate. Clonally expanded cells were then grown in CMRL-1066 medium containing $5.5 \mathrm{mM}$ glucose, $2 \mathrm{mM}$ L-glutamine, $10 \%$ fetal bovine serum, $100 \mathrm{ng} / \mathrm{ml} \mathrm{EGF}$, and $10 \mathrm{ng} / \mathrm{ml}$ fibroblast growth factor 2 .

\section{$R N A$ isolation and quantitative PCR}

RNA was isolated from either population of cells or single cells using Trizol (Invitrogen) as per the manufacturer's instructions. cDNA was prepared using a 'High Capacity cDNA Reverse Transcription Kit' (Applied Biosystems, Foster City, CA, USA). PCR was performed in $5 \mu$ reactions in 96-well plates using $100 \mathrm{ng}$ cDNA input (prepared from $100 \mathrm{ng}$ of total RNA) and TaqMan Fast Universal PCR Master Mix (Applied Biosystems). Primers and probes were 'Assay-on-Demand' (Applied Biosystems).

Single cell PCR was carried out using a protocol described elsewhere (Joglekar et al. 2009). Briefly, single cells were picked up either by manual micromanipulation (pipettes/ capillaries) or by automated sorting (using flow cytometry: FACS Vantage, or laser pressure catapulting microscopy: PALM microbeam 4 system on Zeiss Axio-Observer Z1). Single cells collected by either of these methods were placed directly into Trizol and resuspended several times. Since single cell PCR involves the handling of a very low amount of RNA, we used $1 \mu \mathrm{l}(1 \mu \mathrm{g} / \mu \mathrm{l})$ nuclease-free glycogen as a carrier for RNA isolation. RNA isolation was carried out in a total volume of $20 \mu \mathrm{l}$. Following isolation, resulting RNA is resuspended in nuclease-free water and immediately processed to obtain cDNA. Gene transcript analysis is then carried out using 7500 FAST real-time PCR (Applied Biosystems) using cDNA input volume of $1 \mu \mathrm{l}$ in a final reaction volume of $5 \mu \mathrm{l}$. Using this modification, we have been able to assess transcript abundance of 20 genes at a time from a single cell using duplex TaqMan-based real-time PCR. Part numbers for each assay (Applied Biosystems) are listed in Supplementary Table 1, see Supplementary data in the online version of the Journal of Endocrinology at http://joe. endocrinology-journals.org/content/vol201/issue1/.
Antibodies, immunostaining, and in situ hybridization

Rabbit polyclonal antibody to human pancreatic polypeptide (PP), guinea pig anti-insulin (Linco Research, Inc., St Charles, MO, USA), rabbit anti-somatostatin (Dako, Santa Barbara, CA, USA), mouse anti-glucagon (Sigma), and mouse monoclonal anti-vimentin (Chemicon, Temecula, CA, USA) are used at 1:100 dilution. Mouse monoclonal anti-cytokeratins-7 and -19 , mouse monoclonal anti-ki67 antibodies (Dako), goat anti-amylase (Santacruz Biotechnology Ltd, Santa Cruz, CA, USA), rabbit anti-Von Willebrand Factor (VWF), mouse anti-nestin (Chemicon), and mouse anti-smooth muscle actin (Sigma) were used at 1:200 dilution. Antibody to $\beta$-catenin (BD Biosciences, Franklin Lakes, NJ, USA) is used at 1:500 dilution. Mouse anti-CD31, PE-labeled anti-CD44, and PE-labeled antiCD90 (BD Biosciences) were used at 1:100 dilution. Human pancreatic duct cell-specific antibody (AB2008: generous gift from the Beta Cell Biology Consortium) was used at 1:200 dilution. Alexa-Fluor 488, 546, and $633 \mathrm{~F}\left(\mathrm{ab}^{\prime}\right)_{2}$ secondary antibodies (Molecular Probes, Eugene, OR, USA) were used at 1:200 dilution. Hoechst 33342 or propidium iodide was used to visualize nuclei. For immunostaining, cells were fixed in $4 \%$ fresh paraformaldehyde, permeabilized using chilled $50 \%$ methanol, blocked in 4\% normal donkey serum, and incubated with primary antibodies at $4{ }^{\circ} \mathrm{C}$ overnight. Cells were then washed with calcium-magnesium containing PBS and incubated with secondary antibodies at $37^{\circ} \mathrm{C}$ for $1 \mathrm{~h}$. Cells were washed again and mounted in Vectashield mountant containing Hoechst 33342. In situ hybridization and antibody labeling were performed as described previously (Gershengorn et al. 2004). All cell preparations were scanned and assessed using Zeiss LSM 510 laser confocal microscope. All images were captured after setting their thresholds below saturation. Laser power and other parameters were kept identical for all samples. Results presented are representative fields from at least five different experiments.

\section{Lineage tracing}

To follow propagation of insulin-producing cells, two thymidine analogs, CldU and IdU (Sigma), were used as described previously (Teta et al. 2007). CldU (10 $\mu \mathrm{M})$ was added to freshly isolated islets and incubated in SCM for 2 days followed by 1 day of washout (no analog) and again a 2-day pulse with IdU $(10 \mu \mathrm{M})$. Cells were fixed on fifth day from isolation. Immunostaining was carried out using antibodies for CldU (Accurate Chemicals, Westbury, NY, USA), IdU (BD Biosciences), and insulin (Linco Research, Inc.) at 1:100 dilution as per the procedure described earlier (Teta et al. 2007). Stained cells are visualized using Zeiss LSM 510 confocal microscope. Time-lapse photography was carried out on Zeiss Axiovert 200 system for $18 \mathrm{~h}$ at $37^{\circ} \mathrm{C}$ in $5 \% \mathrm{CO}_{2}$. Each picture was taken at an interval of $5 \mathrm{~min}$. 


\section{Chromatin immunoprecipitation}

Human fetal islets (day 6), mesenchymal cells generated at passage 10 (1000-fold expansion) or passage 20 (million-fold expansion), and adult human bone marrow-derived mesenchymal cells were used for chromatin immunoprecipitation using a slight modification of protocol described elsewhere (Hauser et al. 2002). Briefly, cells were cross-linked using $1 \%$ formaldehyde (Sigma) and sonicated to generate $300 \mathrm{bp}$ to $1 \cdot 2 \mathrm{~kb}$ DNA fragments. Quality and quantity of chromatin were checked at this stage. Chromatin was immunoprecipitated using $2 \mu \mathrm{g}$ of specific dimethyl antibodies for $\mathrm{H} 3 \mathrm{~K} 4$ and H3K9 (Millipore Inc., Bedford, MA, USA). Precipitation cocktail includes protein A/G plus beads (Pierce, Rockford, IL, USA), sonicated salmon sperm DNA (Amersham), and BSA (Sigma). Rabbit IgG (Upstate) was used as isotype control. Chromatin was eluted using $2 \%$ SDS, $0 \cdot 1 \mathrm{M}$ $\mathrm{NaHCO}_{3}$, and $10 \mathrm{mM}$ dithiothreitol. Cross-links are reversed by incubating the eluted chromatin in $4 \mathrm{M} \mathrm{NaCl}$ for $4 \mathrm{~h}$ at $65{ }^{\circ} \mathrm{C}$. This was followed by proteinase-K digestion and DNA extracted using phenol-chloroform-isoamyl alcohol was dissolved in nuclease-free water. Insulin promoter-specific primers were used to carry out PCR on input, immunoprecipitated, and isotype control DNA.

\section{Results}

We observed that following exposure to SCM, cells within freshly isolated and handpicked human fetal islets migrate and proliferate rapidly to form a confluent monolayer of fibroblast-like cells in the period of 15 days from isolation (Fig. 1A-C). These cells show remarkable ability to proliferate (Fig. 1E, H and Supplementary movie 1, see Supplementary data in the online version of the Journal of Endocrinology at http://joe.endocrinology-journals.org/ content/vol201/issue1/) with a doubling time of around $48 \mathrm{~h}$. Fibroblast-like cells generated during in vitro expansion showed immunopositivity to mesenchymal proteins vimentin, smooth muscle actin (Fig. 1F) as well as cell surface markers CD44 and CD90 (Supplementary Fig. 1, see Supplementary data in the online version of the Journal of Endocrinology at http://joe.endocrinology-journals.org/ content/vol201/issue1/). Immunostaining for islet hormone-containing/pancreatic duct epithelial cells as well as pancreatic exocrine and endothelial cells (Fig. 2) was carried out during the initial 15 days of expansion. We did not see immunopositivity to any of these pancreatic proteins in the majority of mesenchymal cells that were obtained at 15 days of in vitro expansion. Islet hormone-containing cells were found at much lower abundance $(2-5 \%)$ by day 15 . Since pro-insulin transcript has a longer half-life and could be detected by fluorescence in situ hybridization, we performed FISH for pro-insulin on day 3 islets that also demonstrated mesenchymal-like cells migrating out from them (Fig. 1G). Day 3 fetal islets show vimentin-immunopositive cells, some of which also co-expressed pro-insulin transcripts.

Islets were disrupted with trypsin to obtain single cells. These single cells were labeled with cell tracker dye and placed in cloning cylinders on alpha-numeric cover slips (Fig. 3A). The cover slips were manually screened for the presence of single cells, which were then followed for at least 3 weeks to assess their ability to proliferate as single cells. We observed that $1514(37 \%)$ of a total of 4128 single cells proliferate to form monolayers of mesenchymal cells in vitro. Clonally derived mesenchymal cells obtained from fetal human islets showed similar expression (Fig. 3B) of mesenchymal proteins (vimentin, smooth muscle actin, nuclear $\beta$-catenin, and the intermediate filament protein nestin).

Islet-derived cell population was quantitatively assessed for various epithelial and mesenchymal gene transcripts at different time points of expansion using TaqMan-based duplex PCR (Table 1). Epithelial gene transcript abundance decreases while that of the mesenchymal genes increases with increasing period of expansion. To confirm these findings at the single cell level, we looked at transcript changes in single cells obtained from freshly isolated fetal human pancreatic islets and the cells expanded from them. With a modification of our previously described protocol (Gershengorn et al. 2004), we could quantify 20 different gene transcripts within a single cell. During days 2 to 7 , when the number of viable cells remained constant, several cells were positive for proinsulin, although transcript levels were distributed over two orders of magnitude. From day 7 to 15, the level of pro-insulin transcript declined in individual cells, but the proportion of pro-insulin-transcript-containing cells remained constant. Moreover, though the total number of cells doubled from day 7 to 10 and again from day 10 to 15 , the number of proinsulin-positive cells did not decrease proportionately. We then optimized conditions wherein islets do not show any detectable insulin-positive cells following exposure to the $\beta$-cell-specific toxin, STZ. Single cells picked from these populations showed very few proinsulin-containing cells (Fig. 3C). We then also looked at the possibility of other islet cells contributing to mesenchymal cells generated in vitro. Since pancreatic islets are highly vascularized, we checked whether endothelial cells, which constitute a significant number of cells within the islets, contribute to mesenchymal cells generated in vitro. Assessment of PECAM1 gene transcripts from single cells (Fig. 4) and immunostaining for CD31 and VWF (Fig. 2) suggests that endothelial cells do not survive in our culture conditions. Mesenchymal gene transcripts (VIM, SNAI2) were retained for 10 days, while other epithelial/islet (pro-) hormone gene transcripts $(C D H 1, g c g, s s t)$ showed a gradual loss (Fig. 4) during these 10 days of culture. Though cytokeratin-19 transcript-positive cells were seen at day $2(79 \cdot 2 \%$ cells), their number did not increase $(41.7 \%$ at day 10$)$ during in vitro culture. During this time, the number of ki67 transcript-positive cells increased from $8 \cdot 3$ (day 2) to $47 \cdot 9 \%$ (day 10 ). Of the total pro-insulinpositive cells assessed (Fig. 4), $15 \%$ on day 7 and $22 \%$ on 
day 10 co-expressed ki67 and pro-insulin gene transcripts, respectively. We also saw co-expression of insulin and Ki67immunopositive cells in day 4 populations of islets (Fig. 1E).

To check if insulin-containing cells within fetal human islets represent a proliferating population of cells, we carried out thymidine analog-based lineage tracing using a protocol described earlier (Teta et al. 2007). Five days after islet isolation, we observed around $40 \%$ of insulin-containing cells co-expressing both thymidine analogs thereby confirming
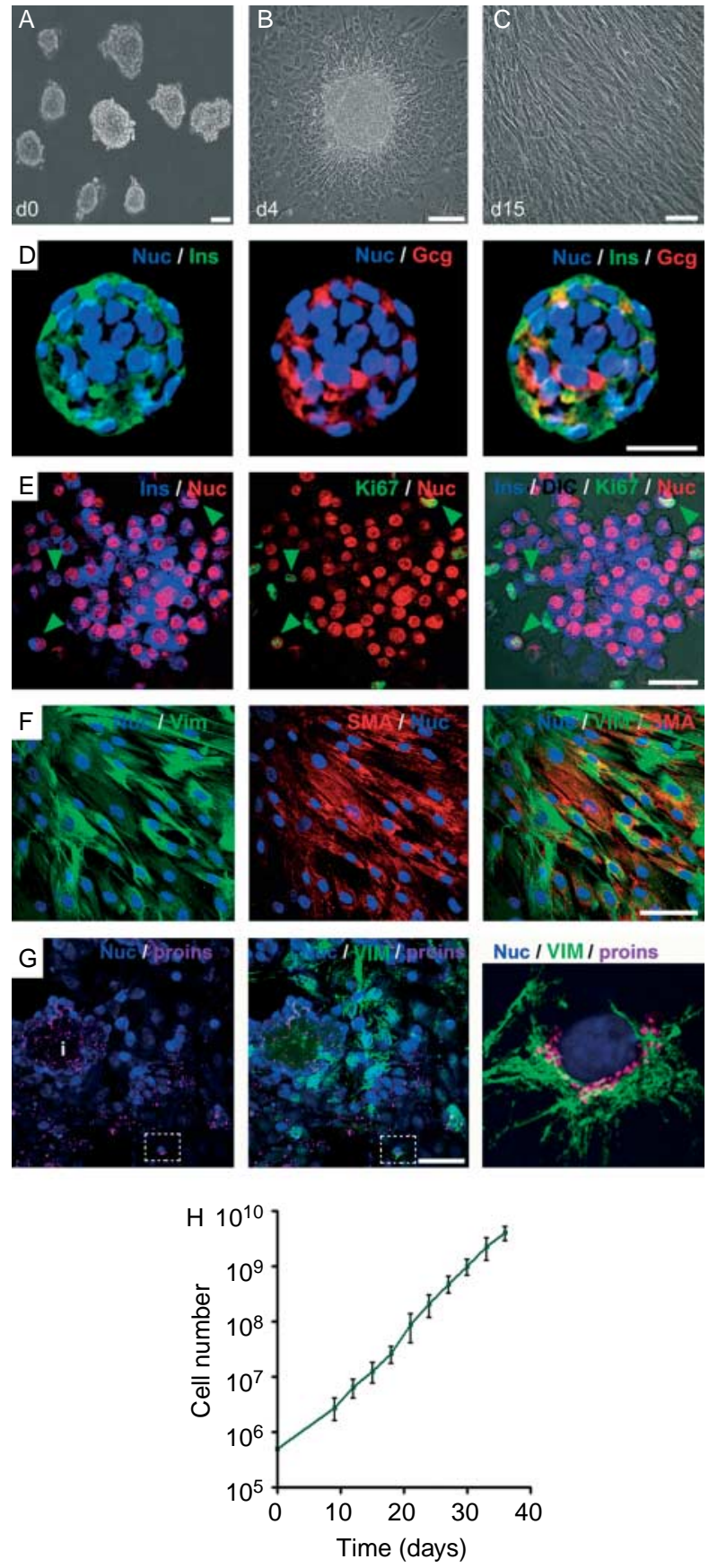

that these insulin-containing cells can go through at least two rounds of replication (Fig. 5A) during the initial 5 days of in vitro expansion. Since mesenchymal populations obtained from human fetal islets were seen to proliferate several million-fold in vitro, we assessed the possible contribution of insulin-producing cells to mesenchymal populations generated in vitro. Here, we performed chromatin immunoprecipitation to estimate dimethylation of specific histones, which are known to be permanent/heritable marks of active insulin promoter conformation. We found that islet-derived cells showed significantly higher levels of me2-H3K4, but not me2-H3K9 (Fig. 5B) at insulin promoter region in day 6, passage 10 as well as passage 20 cells. On the other hand, adult human bone marrow-derived mesenchymal cells did not show a detectable level of $\mathrm{H} 3 \mathrm{~K} 4$ dimethylation (a mark of active gene), but a significant $\mathrm{H} 3 \mathrm{~K} 9$ dimethylation (mark of inactive genes) at insulin promoter region.

\section{Discussion}

Several previous attempts (Beattie et al. 1997, 1999, Schmied et al. 2001, Bouckenooghe et al. 2003, Gershengorn et al. 2004, Rukstalis \& Habener 2007) to maintain adult pancreatic islet $(\beta-)$ cells in culture have resulted in loss of hormone-producing cells and generation of mesenchymallike cell populations that produce vimentin. Though mouse islet $\beta$-cells do not contribute to proliferate populations of mesenchymal cells (Atouf et al. 2007, Chase et al. 2007, Morton et al. 2007, Teta et al. 2007, Weinberg et al. 2007), these may be age-related ((Teta et al. 2005, Rankin et al. 2006) and personal correspondence with Jake Kushner) or simply

Figure 1 Populations of human fetal pancreatic islets demonstrate mesenchymal cell types during in vitro culture. (A) Freshly isolated and handpicked islets (day 0: $\mathrm{d} 0$ ) after isolation attached to the culture plates and epithelial cells within islets begin to migrate out of them (B). Mesenchymal cells derived from islets are so proliferative that they form confluent monolayers (C) by day 15 . Islets obtained from third trimester fetal pancreas show hormonecontaining cells after isolation (D). By day 4, few cells coming out of such islets express proliferation marker Ki67. Insulin-containing cells that co-express Ki67 are shown with arrowheads (E). DIC, differential interference contrast microscopy is used to visualize other cells in the field. Mesenchymal cells obtained in these islet cultures continue to express vimentin (green) as well as smooth muscle actin (SMA: red) even 60 days (F) after isolation. By 3 days after isolation, cells were probed for pro-insulin transcript (purple) by FISH (G) and then immunostained for vimentin (green). Though pro-insulin is not detected in the majority of the cells that have migrated away from islet (i), vimentin is seen to be co-expressed in pro-insulin transcript-positive cell in or away from the islet cluster (G). A 3D reconstruction of one such cell (white box) is shown at higher magnification in the rightmost panel (in G). Growth potential of second trimester human fetal pancreatic islet-derived mesenchymal cells was assessed during in vitro expansion of isolated islets. Islet-derived mesenchymal cells show exponential cell growth for over 20 passages. Representative growth profile of three different islet preparations during the initial 40 days of culture is shown in $' \mathrm{H}^{\prime}$. Bar $=50 \mu \mathrm{m}$. 


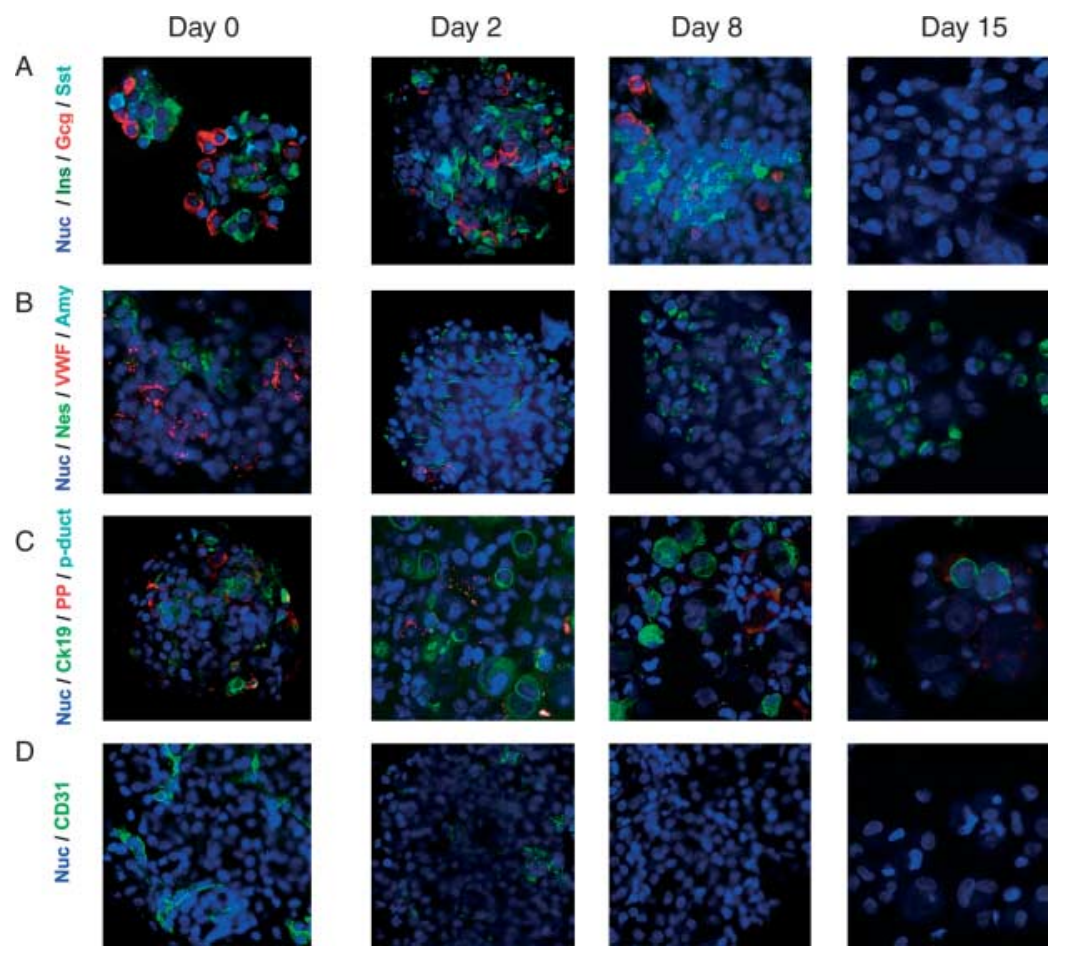

Figure 2 Pancreatic exocrine, endocrine, duct, and endothelial cell proteins during in vitro expansion. Human fetal islets isolated from second trimester pancreas were harvested at day- $0,-2,-8$, and -15 . Islets or islet-derived monolayers are trypsinized, cytospun, and immunostained for endocrine hormones (Ins, insulin; Gcg, glucagons; Sst, somatostatin and PP, pancreatic polypeptide), pancreatic duct cell markers (P-duct, pancreatic duct and CK7-19, cytokeratin-7 and -19), endothelial proteins (VWF, Von Willebrand Factor and CD31), exocrine marker amylase (Amy), and intermediate filament protein (Nes, nestin). Bar $=20 \mu \mathrm{m}$.

due to the inherent difference in mouse and human cell systems. As has been demonstrated in several studies published so far, mouse islets have a typical architecture with islet $\beta$-cells in the core, surrounded by other non- $\beta$ islet cells (Halban et al. 1987, Andersson et al. 1996, Brissova et al. 2005, Cabrera et al. 2006). However, if glucagon-, somatostatin- or PPproducing cells in mouse islets undergo proliferation in vitro, remains unclear. Very recently, adult human pancreatic $\beta$-cells were shown to proliferate in vitro (Russ et al. 2008). These authors used a lentivirus-based lineage tracing system to follow pro-insulin-expressing cells. Though they were able to achieve much better efficiency in $\beta$-cell labeling with this dual virus system, all islet $\beta$-cells are not labeled. Here, we have taken seven different methods to assess the proliferative potential of insulin-producing cells from human fetal pancreas.

By carrying out the immunostaining of islet cells, we demonstrate that few insulin-containing cells also co-express Ki67, a proliferation antigen at day 4 of in vitro expansion (Fig. 1E). Combined FISH and immunocytochemistry for pro-insulin transcript and vimentin demonstrate that some of the cells that are producing mesenchymal proteins also express insulin transcripts, suggesting that vimentin-immunopositive cells, which appear during in vitro expansion, came from cells that initially expressed insulin-transcripts. As mentioned earlier, insulin transcript has a long half-life $(\sim 48 \mathrm{~h})$ and is detectable in cell populations for up to 10 passages ( $>6$ weeks of in vitro culture; Table 1). To understand the co-expression of islet and mesenchymal gene transcripts in a single cell, we used a novel method of assessing up to 20 different gene transcripts in a single cell by quantitative duplex real-time PCR. These data demonstrate that though cells undergo proliferation, the number of insulin-transcript-containing cells did not decrease significantly. The number of insulin and ki67 transcript co-expressing cells increases during in vitro expansion. Our results thus demonstrate that insulinproducing cells in islet populations do not die, as suggested for mouse $\beta$-cells, but rather show an increase in abundance of proliferative gene transcripts indicating their duplication during in vitro culture. Indeed, time-lapse observations with islet-like clusters demonstrate that cells within such clusters begin to proliferate as they start coming out of these clusters (Supplementary movie 1). Several studies have demonstrated earlier (Bennett \& Pegg 1981, Saini et al. 1996, Lenzen 2008) that $\beta$-cells undergo cell death following exposure to STZ, a $\beta$-cell-specific toxin. In order to understand the cell populations that grow out of islets in the absence of $\beta$-cells, 
A
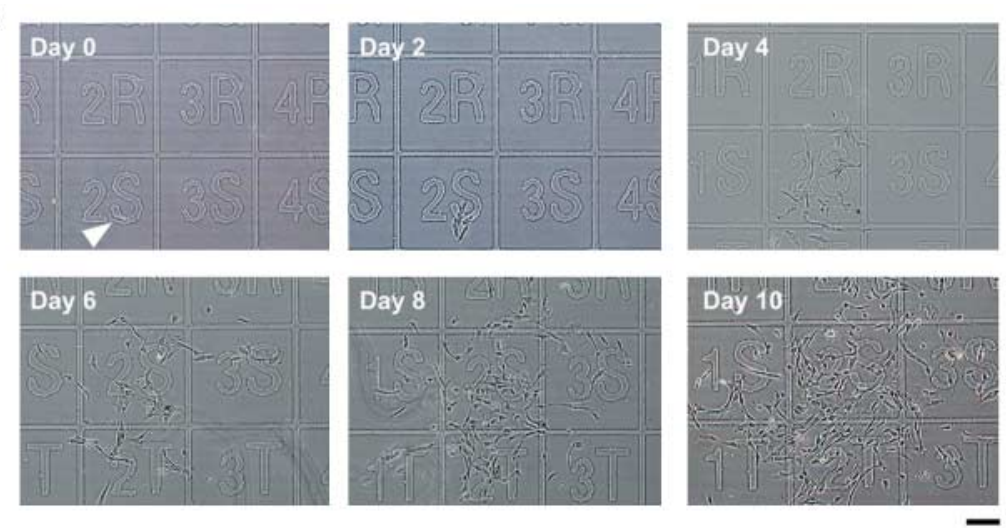

B
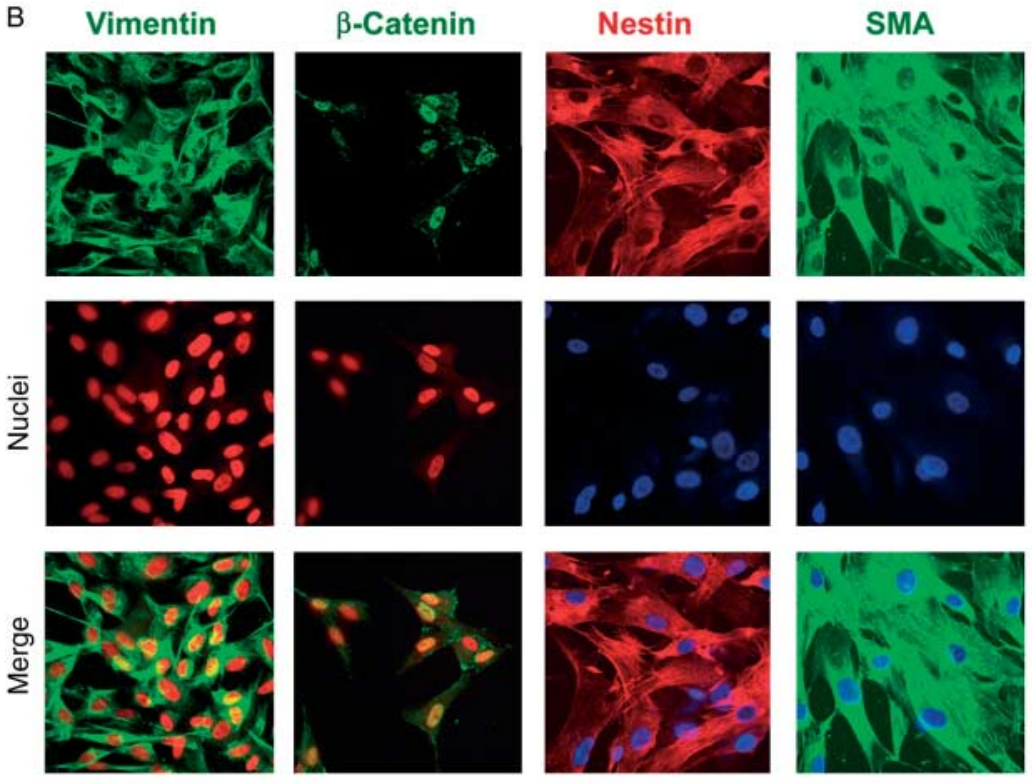

C
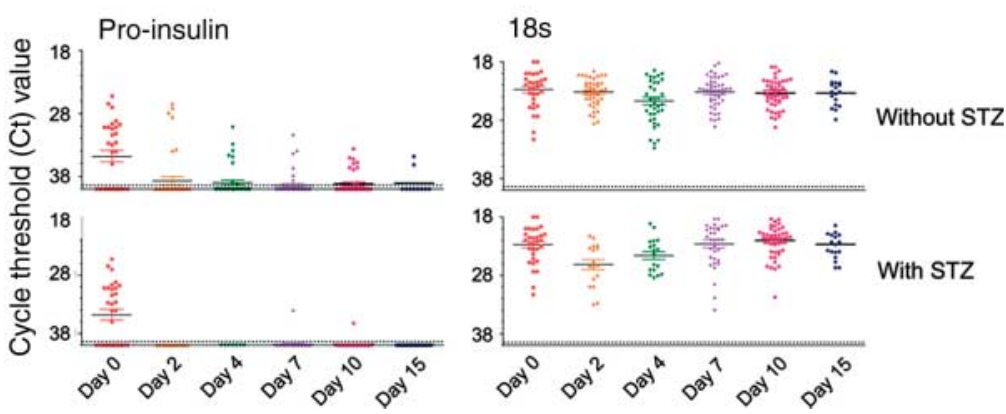

Figure 3 Characterization of mesenchymal markers in single cells. Clonal propagation was assessed in cells isolated from second trimester human fetal islets. Panel ' $A$ ' demonstrates the expansion of a single cell (pointed out with arrowhead in ' $2 \mathrm{~S}^{\prime}$ ) plated on photoetched alpha-numeric cover slip during 10 days of exposure to growth-promoting medium. Million-fold expanded populations of such clonally grown fetal islet cells were immunostained for mesenchymal markers (B). Clonally derived mesenchymal cells show uniform expression of vimentin, SMA, nestin, and nuclear $\beta$-catenin (B). Images are representative micrographs obtained from three different clones. Freshly isolated human pancreatic islets were dispersed to single cells and exposed to media containing $1 \mathrm{mM} \beta$-cell-specific toxin, streptozotocin (STZ) or carrier (buffer). Panel 'C' demonstrates the measurement of pro-insulin (left panels) and 185 rRNA (right panels) from single cells at 0-, 2-, 4-, 7-, 10-, and 15-days of isolation. We observe a steady decline in number as well as level of expression of pro-insulin, in cells that are not exposed to streptozotocin (STZ). Cells exposed to STZ show none or rare pro-insulincontaining cells. Pro-insulin and $18 \mathrm{~S}$ expression in individual cells and their mean shown here represent 2 of the 11 different transcripts (Supplementary Fig. 3) assessed in these single cells. Bar $=25 \mu \mathrm{m}$. 
Table 1 Passage-wise quantitative analysis of various epithelial and mesenchymal gene transcripts. Data are means of $\Delta$ cycle threshold values from five different third trimester islet preparations. Human fetal pancreatic islets immediately after isolation (day 0 ) and mesenchymal cells obtained from them at different passages (passages 4, 7, 9, and 11) were harvested and RNA was isolated. Epithelial genes as well as pancreas-specific transcription factors analyzed in these cells were found to decrease in their transcript abundance, while the mesenchymal gene transcripts increase.

\begin{tabular}{|c|c|c|c|c|}
\hline Day 0 & Passage 4 & Passage 7 & Passage 9 & Passage 11 \\
\hline 13 & 31 & 36 & $>39$ & $>39$ \\
\hline 16 & 28 & 35 & 36 & 36 \\
\hline 15 & 31 & 32 & 38 & $>39$ \\
\hline 23 & 37 & 38 & 37 & $>39$ \\
\hline 19 & 26 & 26 & 27 & 27 \\
\hline 20 & 24 & 25 & 25 & 27 \\
\hline 21 & 35 & $>39$ & $>39$ & $>39$ \\
\hline 23 & 37 & 37 & 37 & 38 \\
\hline 22 & 29 & 31 & 32 & 34 \\
\hline 24 & 36 & $>39$ & $>39$ & $>39$ \\
\hline 21 & 31 & 32 & 32 & 32 \\
\hline 22 & 33 & 35 & 36 & $>39$ \\
\hline 22 & 26 & 25 & 26 & 27 \\
\hline 31 & 35 & 38 & $>39$ & $>39$ \\
\hline 13 & 12 & 12 & 12 & 12 \\
\hline 23 & 20 & 20 & 20 & 21 \\
\hline 24 & 22 & 23 & 20 & ND \\
\hline 25 & 20 & 19 & 19 & ND \\
\hline 22 & 19 & 19 & 18 & ND \\
\hline 25 & 24 & 23 & 21 & ND \\
\hline
\end{tabular}

ND, not done.

we exposed islet $\beta$-cells to STZ and followed them by confocal microscopy as well as single cell PCR. We observe a significant reduction in the number of pro-insulin transcriptcontaining cells in cell populations that were exposed to STZ.
If mesenchymal cells came from pro-insulin transcript-negative cells, then the doubling of the cell population would have decreased pro-insulin transcript-expressing cells to one-half of the original at day 7 and again by half at day10. If islet $\beta$-cells

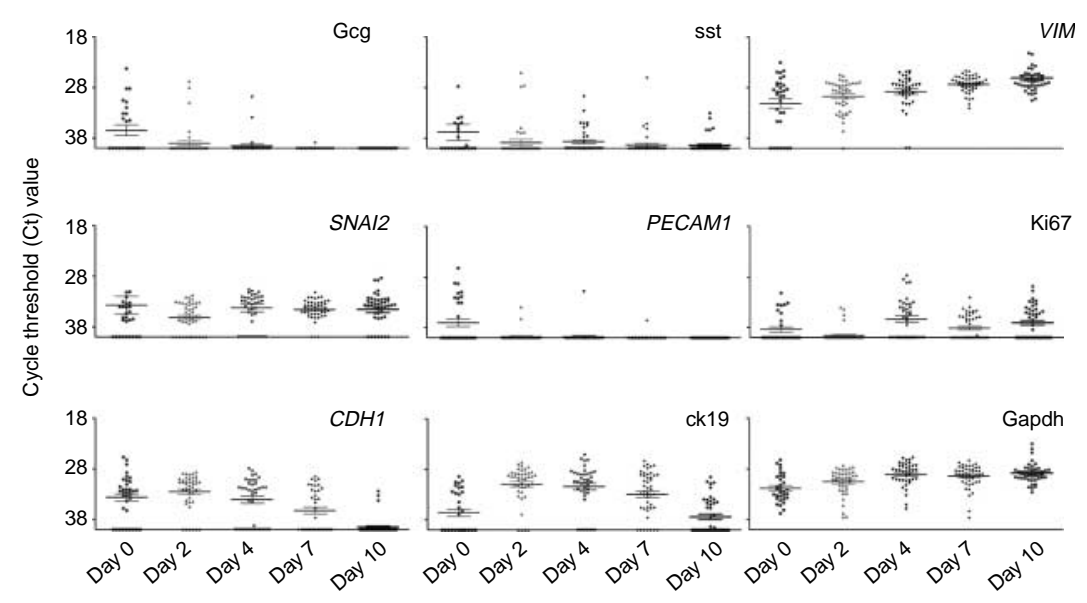

Figure 4 Simultaneous measurements of multiple gene transcripts during in vitro islet culture by single cell PCR. Islets isolated from human fetal pancreas were plated on to tissue culture-treated plates and single cells were picked up at 0-, 2-, 4-, 7- or 10-days of culture. Single cell PCR was carried out for 11 different genes. Glucagon (Gcg), somatostatin (sst), and e-cadherin $(\mathrm{CDH} 1)$ transcripts show gradually reduced expression. PECAM1 was almost undetectable from day 4. Ki67, vimentin (VIM), cytokeratin19 (ck19), and snail2 (SNAI2) transcripts remain stable during these 10 days of culture. Gapdh was used as housekeeping control along with 18S rRNA (Fig. 2). Data represent the results of 48 or 72 single cells obtained from three different preparations during the first 10 days of in vitro culture. 
A
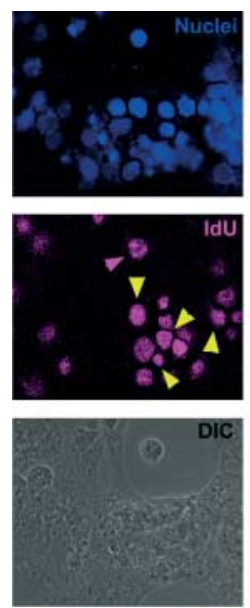
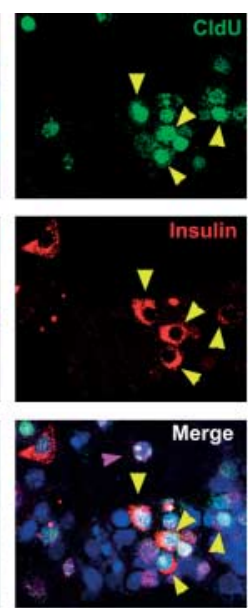

B

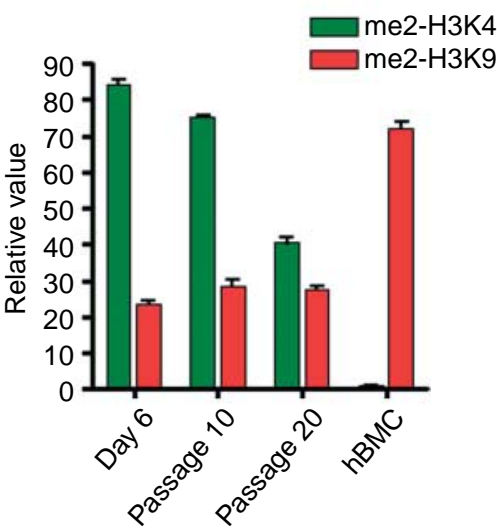

Figure 5 Insulin-producing cells proliferate and contribute to mesenchymal populations generated in vitro. (A) Lineage tracing using two different thymidine analogs (CldU and Idu, see text) demonstrates that some insulin-immunopositive cells incorporate both $\mathrm{CldU}$ and IdU (yellow arrowheads), while fewer incorporate IdU only (purple arrowheads). (B) Chromatin immunoprecipitation (ChIP) for $\mathrm{H} 3 \mathrm{~K} 4$ and $\mathrm{H} 3 \mathrm{~K} 9$ dimethylation at insulin promoter region in day 6 , passage 10, passage 20 islet-derived cells, and human bone marrow mesenchymal cells (hBMCs) was carried out. H3K4 dimethylation (green bars), a mark of active gene conformation was detected in day 6 , passage 10 (1000-fold expanded) and passage 20 (million-fold expanded) islet-derived cells but not in hBMCs. On the other hand, H3K9 dimethylation (red bars), a mark of inactive gene was easily detected at the insulin promoter region of hBMCs, but barely in islet-derived cells. Data represent mean \pm S.E.M. from two fetal preparations.

Bar $=25 \mu \mathrm{m}$.

died during this process, then we would expect to see no significant pro-insulin-transcript-positive cells. However, our data suggest that insulin-producing cells in human pancreatic islets did not die, but rather 'lost' insulin transcript as we continued to grow them in vitro. Clonal analysis of human fetal pancreatic islets cells suggests that $37 \%$ of these were able to proliferate into clonal populations. Based on our immunostaining studies and other reports (Brissova et al. 2005, Cabrera et al. 2006), human islets are known to be made up of $\sim 50 \%$ c-peptide (insulin)-containing cells, $\sim 20 \%$ of glucagon-containing cells, and $\sim 10 \%$ of somatostatin and pp-containing cells. Since we could see clonal expansion in $37 \%$ of cells obtained from fetal islets, one or many of the hormone-producing $(\alpha-/ \beta-/ \delta-/ p p-)$ cells may be proliferating during such in vitro expansion.

Lineage tracing using thymidine analogs is a wellestablished and unbiased method of following proliferating cells. The method involves the use of two different thymidine analogs that can be detected independently using specific antibodies. Here, any cell that goes through the S-phase during the period of pulse would be labeled and hence could be detected by immunostaining. Furthermore, by using specific antibodies for known markers, this method offers the possibility to look at other cell populations that proliferate in vitro. Using the thymidine analog-based labeling, we have seen that around $40 \%$ of insulin-producing cells incorporate the label in 5 days of in vitro expansion.
Since insulin protein has a short half life, it remains undetectable after 3 weeks of in vitro expansion. Hence, it is impossible to follow the $\beta$-cells over a long period of time by labeling them with thymidine analogs. We therefore used a different method to assess the long-term proliferation ability of islet $\beta$-cells. The insulin promoter is known to be differentially methylated in different cell types and these methylation marks are well-established 'histone codes' that determine the active/inactive states of insulin promoter (Francis et al. 2005, Russ et al. 2008). In human islet $\beta$-cells, we do see higher levels of H3K4-me2 (dimethylation at lysine 4 of histone H3), which is well established to be an epigenetic mark of active promoters. In contrast, $\mathrm{H} 3 \mathrm{~K} 9-\mathrm{me} 2$, an epigenetic mark that characterizes an inactive chromatin conformation, is observed in insulin promoter of non-endocrine tissues such as the adult human bone marrow. Our studies demonstrate that active marks of insulin promoter are detectable even after millionfold expansion/proliferation (passage 20) of islet cell populations. The reduction in the levels of these marks during successive passages is probably due to the higher proliferative rate of other (non- $\beta$ )-cells within the population. These studies demonstrate that $\beta$-cell-derived progeny (with active marks at insulin promoter region) is retained even after a million-fold expansion in vitro. In summary, our data support recent findings in adult pancreatic islet cell proliferation and demonstrate that fetal pancreatic $\beta$-cells may proliferate and contribute to mesenchymal populations generated in vitro. 
In summary, we hypothesize here that hormonecontaining cells within human fetal pancreatic islets contribute to the mesenchymal-like cells generated in vitro. By taking multiple approaches, we investigated the possibility of an alternate hypothesis wherein exocrine, ductal or endothelial cells within the pancreas could proliferate in vitro. Our studies using immunostaining and single cell PCR denote that endothelial cells, amylase-containing acinar cells or ck-7/ -19-containing duct cells are rapidly lost during the initial 2 weeks of in vitro expansion. Though we do see PECAM transcripts in mesenchymal cell populations (Table 1), our single cell PCR data suggest that this may be due to very high transcript abundance in fewer cells. Our data obtained from thymidine-analog-based lineage tracing, clonal expansion of islet cells, combined FISH, and immunostaining as well as analysis of active marks of insulin promoter point to the proliferation of insulin-/hormone-containing cells during in vitro expansion. Chromatin immunoprecipitation data obtained however, shows a decrease in the epigenetic marks that signify an active insulin promoter. This is probably due to differences in the proliferation rate of insulin-expressing vs non-insulin-expressing cells during in vitro expansion, extending the possibility that other hormone-expressing cells/stem-like cells contribute to the mesenchymal-like progenitor cells obtained in vitro. We also do not refute the possibility of any other stem-like cells growing/expanding during such in vitro culture. Nonetheless, all the approaches that we have taken collectively point to the potential of hormone-containing cells within human fetal pancreatic islets to proliferate in vitro. The possible proliferation of human islet $\beta$-cells is encouraging. We believe that mesenchymal cells obtained after proliferation of pancreatic islet cells may be better precursors for differentiation to endocrine pancreatic lineage. Present studies being carried out in the laboratory are aimed towards understanding the role of specific chromatin modulators/ncRNAs in differentiation of such islet-committed progenitor cells. Understanding the potential of such human pancreatic islet-derived progenitor cells to differentiate into insulin-producing islet-like cell aggregates may help us in generating lineage committed progenitors for cell replacement therapy in diabetes.

\section{Declaration of interest}

The authors declare that there is no conflict of interest that could be perceived as prejudicing the impartiality of the research reported.

\section{Funding}

This research was supported by the Intramural Research Program of National Center for Cell Science and a microRNA consortium project grant (BT/PR7975/MED/14/1211/2006) to A A H from the Department of Biotechnology, Government of India. M V J is supported by a fellowship from Council of Industrial and Scientific Research (CSIR), Government of India.

\section{Acknowledgements}

The authors would like to acknowledge the support extended by $\mathrm{Dr}$ Shiwalkar, Tarachand General Hospitals and Dr Kurtakoti, Pune Gynecology Foundation in isolation of fetal pancreas. We thank Sushil G Rane, NIDDK, National Institutes of Health for suggestions during preparation of this manuscript. A A H identified the research area, designed and planned the study, and analyzed data. M V J performed all experiments and wrote the first draft. V M J and S V J isolated human pancreas. All authors read, discussed, and agreed on the final draft.

\section{References}

Andersson A, Eizirik DL, Bremer C, Johnson RC, Pipeleers DG \& Hellerstrom C 1996 Structure and function of macroencapsulated human and rodent pancreatic islets transplanted into nude mice. Hormone and Metabolic Research 28 306-309.

Atouf F, Park CH, Pechhold K, Ta M, Choi Y \& Lumelsky NL 2007 No evidence for mouse pancreatic beta-cell epithelial-mesenchymal transition in vitro. Diabetes 56 699-702.

Beattie GM, Cirulli V, Lopez AD \& Hayek A 1997 Ex vivo expansion of human pancreatic endocrine cells. Journal of Clinical Endocrinology and Metabolism 82 1852-1856.

Beattie GM, Itkin-Ansari P, Cirulli V, Leibowitz G, Lopez AD, Bossie S, Mally MI, Levine F \& Hayek A 1999 Sustained proliferation of PDX-1 + cells derived from human islets. Diabetes 48 1013-1019.

Bennett RA \& Pegg AE 1981 Alkylation of DNA in rat tissues following administration of streptozotocin. Cancer Research 41 2786-2790.

Bouckenooghe T, Vandewalle B, Lukowiak B, Kerr-Conte J, Belaich S, Gmyr V, Dubois M, Riachy R \& Pattou F 2003 Modulation of specific beta cell gene (re)expression during in vitro expansion of human pancreatic islet cells. Cell Transplantation 12 799-807.

Brissova M, Fowler MJ, Nicholson WE, Chu A, Hirshberg B, Harlan DM \& Powers AC 2005 Assessment of human pancreatic islet architecture and composition by laser scanning confocal microscopy. Journal of Histochemistry and Cytochemistry $\mathbf{5 3}$ 1087-1097.

Cabrera O, Berman DM, Kenyon NS, Ricordi C, Berggren PO \& Caicedo A 2006 The unique cytoarchitecture of human pancreatic islets has implications for islet cell function. PNAS 103 2334-2339.

Chase LG, Ulloa-Montoya F, Kidder BL \& Verfaillie CM 2007 Islet-derived fibroblast-like cells are not derived via epithelial-mesenchymal transition from Pdx-1 or insulin-positive cells. Diabetes 56 3-7.

Dor Y, Brown J, Martinez OI \& Melton DA 2004 Adult pancreatic beta-cells are formed by self-duplication rather than stem-cell differentiation. Nature 429 41-46.

Francis J, Chakrabarti SK, Garmey JC \& Mirmira RG 2005 Pdx-1 links histone H3-Lys-4 methylation to RNA polymerase II elongation during activation of insulin transcription. Journal of Biological Chemistry 280 36244-36253.

Gershengorn MC, Hardikar AA, Wei C, Geras-Raaka E, Marcus-Samuels B \& Raaka BM 2004 Epithelial-to-mesenchymal transition generates proliferative human islet precursor cells. Science 306 2261-2264.

Halban PA, Powers SL, George KL \& Bonner-Weir S 1987 Spontaneous reassociation of dispersed adult rat pancreatic islet cells into aggregates with three-dimensional architecture typical of native islets. Diabetes 36 783-790.

Hauser C, Schuettengruber B, Bartl S, Lagger G \& Seiser C 2002 Activation of the mouse histone deacetylase 1 gene by cooperative histone phosphorylation and acetylation. Molecular and Cellular Biology 22 $7820-7830$.

Joglekar MV, Joglekar VM \& Hardikar AA 2009 Expression of islet-specific microRNAs during human pancreatic development. Gene Expression Patterns 9 109-113.

Kover K \& Moore WV 1989 Development of a method for isolation of islets from human fetal pancreas. Diabetes 38 917-924.

Lenzen S 2008 The mechanisms of alloxan- and streptozotocin-induced diabetes. Diabetologia 51 216-226. 
Morton RA, Geras-Raaka E, Wilson LM, Raaka BM \& Gershengorn MC 2007 Endocrine precursor cells from mouse islets are not generated by epithelial-to-mesenchymal transition of mature beta cells. Molecular and Cellular Endocrinology 270 87-93.

Mutskov VRB, Felsenfeld G \& Gershengorn MC 2007 The human insulin gene displays transcriptionally active epigenetic marks in islet-derived mesenchymal precursor cells in the absence of insulin expression. Stem Cells 25 3223-3233.

Rankin MM, Zajac AL, Teta M, Long SY \& Kushner JA 2006 Beta cell regeneration capacity acutely declines with advanced age. Diabetes $\mathbf{5 5}$ A78-A79.

Ricordi C, Lacy PE \& Scharp DW 1989 Automated islet isolation from human pancreas. Diabetes (Supplement 1) 38 140-142.

Rukstalis JM \& Habener JF 2007 Snail2, a mediator of epithelialmesenchymal transitions, expressed in progenitor cells of the developing endocrine pancreas. Gene Expression Patterns 7 471-479.

Russ HA, Bar Y, Ravassard P \& Efrat S 2008 In vitro proliferation of cells derived from adult human beta cells revealed by cell-lineage tracing. Diabetes 57 1575-1583.

Saini KS, Thompson C, Winterford CM, Walker NI \& Cameron DP 1996 Streptozotocin at low doses induces apoptosis and at high doses causes necrosis in a murine pancreatic beta cell line, INS-1. Biochemistry and Molecular Biology International 39 1229-1236.

Schmied BM, Ulrich A, Matsuzaki H, Ding X, Ricordi C, Weide L, Moyer MP, Batra SK, Adrian TE \& Pour PM 2001 Transdifferentiation of human islet cells in a long-term culture. Pancreas 23 157-171.

Teta M, Long SY, Wartschow LM, Rankin MM \& Kushner JA 2005 Very slow turnover of beta-cells in aged adult mice. Diabetes 54 2557-2567.

Teta M, Rankin MM, Long SY, Stein GM \& Kushner JA 2007 Growth and regeneration of adult beta cells does not involve specialized progenitors. Developmental Cell 12 817-826.

Weinberg N, Ouziel-Yahalom L, Knoller S, Efrat S \& Dor Y 2007 Lineage tracing evidence for in vitro dedifferentiation but rare proliferation of mouse pancreatic beta-cells. Diabetes 56 1299-1304.

Received in final form 31 December 2008

Accepted 26 January 2009

Made available online as an Accepted Preprint 26 January 2009 